\title{
Parry Romberg Syndrome: Literature Review and Report of Three Cases
}

\author{
N. Girish $\operatorname{Kumar}^{1}$ (1) $\cdot$ Brig S. Maurya ${ }^{2}$ Col S. Sudeep ${ }^{3}$
}

Received: 31 May 2018/Accepted: 16 August 2018/Published online: 18 August 2018

(C) The Association of Oral and Maxillofacial Surgeons of India 2018

\begin{abstract}
Parry Romberg Syndrome or Progressive Hemifacial Atrophy is a rare disease usually affecting one side of face with loss of soft and hard tissues. The disease appears suddenly and is usually self-limiting in 2-10 years time. The loss of soft and hard tissue leads to aesthetic and functional deficits which are compounded by the presence of associated symptoms like neuralgia, migraine, epilepsy and ocular involvement. The degree of deformity depends on the age at which the disease manifests first; the younger the age, the more severe the deformity. These patients undergo severe psychological trauma and social problems. The exact etiology is not known, and treatment is largely cosmetic. A report of three cases and a literature review is presented.
\end{abstract}

Keywords Parry Romberg Syndrome · Progressive Hemifacial Atrophy · Dermal fat graft · Porous polyethylene implant $\cdot$ Temporalis myofascial flap

\section{Introduction}

Parry Romberg Syndrome, also known as Progressive Hemi facial Atrophy, is a rare disease of unknown etiology first reported by Caleb Parry in 1825 and then described by Moritz Romberg in 1846 [1]. The term Progressive Hemi

N. Girish Kumar

nanukuttankumar@gmail.com

1 Department of Oral and Maxillofacial Surgery, PMS College of Dental Science and Research, Golden Hills, Vattapara, Thiruvananthapuram 695028, India

2 Command Hospital, Chandimandir, India

3 Command Military Dental Centre, Chandimandir, India facial Atrophy was coined by Eulenberg in 1871 [2]. It is characterized by the progressive and self-limited painless loss of soft tissue and in some cases hard tissues of one side of the face, usually the left. The disease starts with the atrophy of the subcutaneous tissue with thinning of the dermis and darkening of the skin. When the onset is before the second decade, underlying muscle and bone will also be involved. This progresses for a period of 2-10 years and then enters a stable phase. The loss of soft and hard tissue leads to aesthetic and functional deficits which are compounded by the presence of associated symptoms like neuralgia, migraine, epilepsy and ocular involvement. The degree of deformity depends on the age at which the disease manifests first; the younger the age the more severe the deformity. These patients undergo severe psychological trauma and social problems.

Even though Parry Romberg Syndrome was first described as early as 1825 , the evidence of the disease dates back to ancient Egypt with mummies showing features of Progressive Hemi facial Atrophy [3]. Parry Romberg Syndrome remains a poorly understood disease. Different types of presentations and nomenclatures have been provided in pediatric, neurologic, plastic surgery, dermatologic, ophthalmic and other literature [4]. The disease being rare with only a few case reports, the exact incidence in the population is not known. Stone reported an incidence of 1:700,000 [5].

Most of the studies on this condition are case reports. The largest collection of cases studied was by Stone in 2003 by recruiting 205 patients from the "Romberg's Connection" - a Web site that brought together patients with this disorder. We present cases reported to our center from 2009 to 2013. 


\section{Case Report}

\section{Case 1}

A 19-year-old boy reported to our center for correction of facial asymmetry. The patient noticed a gradual change in appearance 3 years before with loss of prominence of the lower half of face on the left side. After a period of 2 years, the condition stabilized leaving an obvious defect on the left side. On examination, there was facial asymmetry with a deficient soft tissue on the left side in lower half (Fig. 1). There was no bony involvement. There were no other relevant findings in the general and local examination. The patient was taken up for augmentation of soft tissue of the lower face on the left side with dermal fat graft taken from the right flank under GA (Fig. 2). Postoperative period was uneventful, and good symmetry was achieved. Patient is under follow-up. The results have been stable even after a period of 2 years (Fig. 3).

\section{Case 2}

A 18-year-old girl was referred to our center for correction of facial asymmetry. The patient was a known case of Parry Romberg Syndrome and had undergone surgery to place tissue expander in the submandibular region which got infected and was removed. She also had a fat graft placed in the face which resorbed completely. On examination, there was involvement of the midface and lower face on the left side with a clear vertical line between the

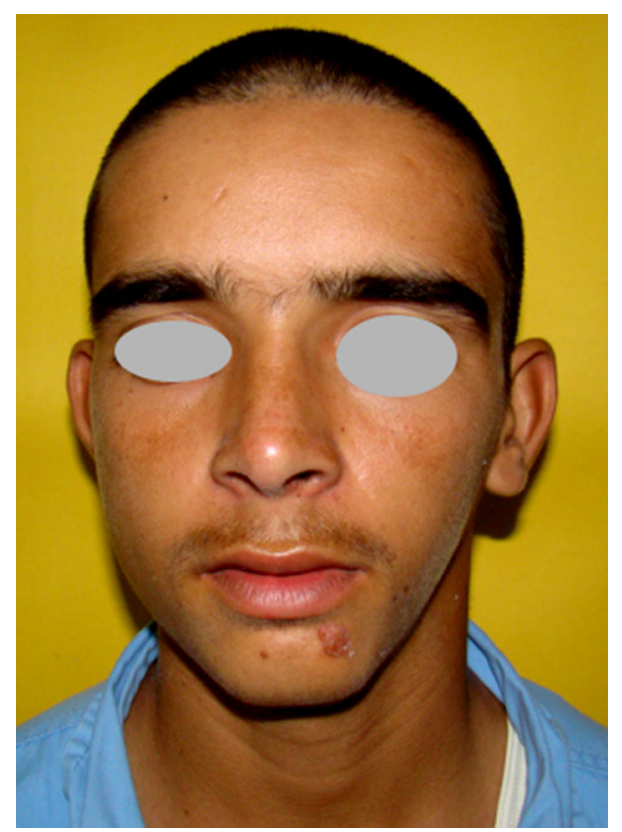

Fig. 1 A case of Parry Romberg Syndrome showing mild loss of tissues in lower half of face on the left side involved and uninvolved tissue in the midline of the lower lip (Fig. 4). CT scan of the facial bones did not show any abnormality. There was a scar in the submandibular region overlying the mandible which was the site of placement of tissue expander. There was mild hemiatrophy of the tongue also (Fig. 5). Since the atrophy involved a larger area, it was decided to tackle the problem in stages. First the angle region was augmented with repositioning of temporalis and the resultant defect in the temporal region was restored with porous polyethylene implants (Fig. 6). The rest of the soft tissue overlying the mandible and the lower lip was augmented with dermal fat taken from the left flank (Fig. 7). Porous polyethylene implant was used to augment the resorbed lower face and fat injection given in the midface (Figs. 8, 9). Reasonably good aesthetics were achieved at the end of 2 years (Fig. 10).

\section{Case 3}

An 11-year-old boy reported to our center for correction of facial deformity. On examination, he had severe atrophy of the skin and subcutaneous tissue on the left side with marked hyperpigmentation (Fig. 11). There was involvement of the bony structure also. However, there were no associated ocular or neurologic signs or symptoms. The change has been noticed 1 year back (Fig. 12). Since he reported the onset of symptoms 1 year back, the patient is on follow-up for stabilization of the disease process before planning intervention (Table 1).

\section{Discussion}

Parry Romberg Syndrome is a rare disease characterized by sudden loss of hard and soft tissue of one side of face. The etiopathogenesis of this disease is still unclear. The prominent theories include autoimmune disorder, cutaneous neuropathy, vascular abnormality and lastly sympathetic dysregulation [6-10]. The incidence and clinical features of this disease are poorly understood because of the rarity of this disease, a lack of clear cut criteria for diagnosis and the frequent overlap with En Coup de Sabre (ECDS). Few authors believe they are different grades of the same disease [11, 12]. Parry Romberg Syndrome may present in a variety of clinical manifestations starting from a barely perceptible asymmetry to severe disfigurement with neurologic and ophthalmic symptoms. Where the atrophy meets the normal tissues, there is usually a clear demarcating line which unlike that of En Coup de Sabre is not sclerotic. The line in ECDS is inevitably seen between the eyebrow and hairline and not below the level of eyebrow. In PRS, the line is seen in the lower face also. 

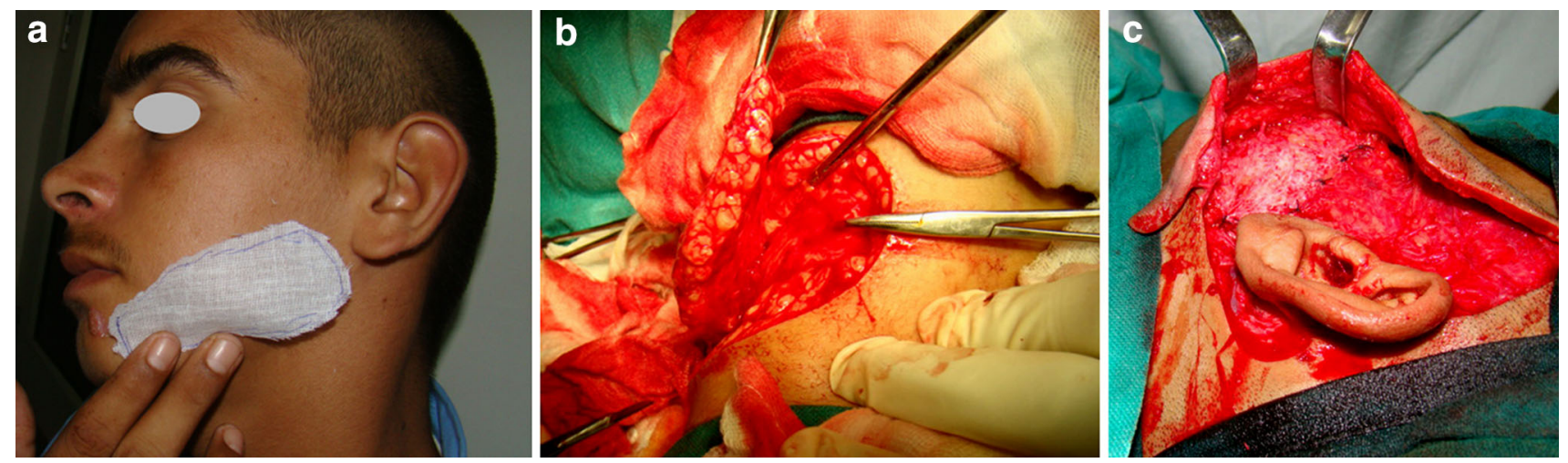

Fig. 2 Harvesting of dermal graft a marking of the defect, $\mathbf{b}$ harvesting the dermal fat graft, $\mathbf{c}$ insetting the graft

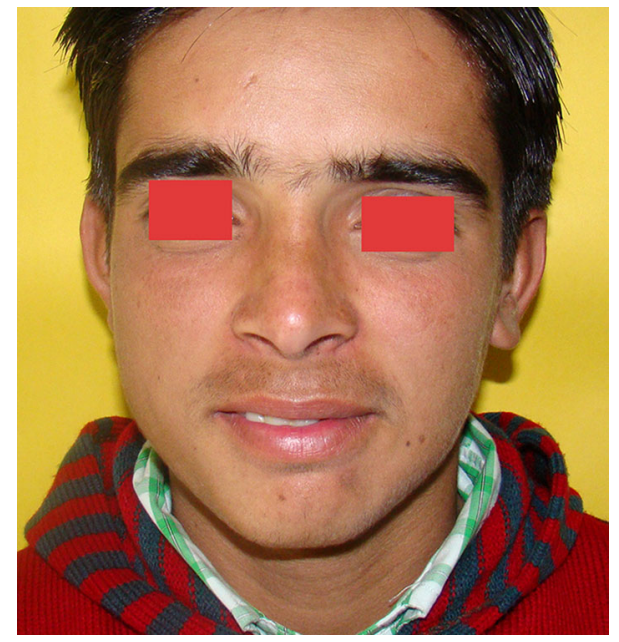

Fig. 3 Postoperative photograph 2 years post-op

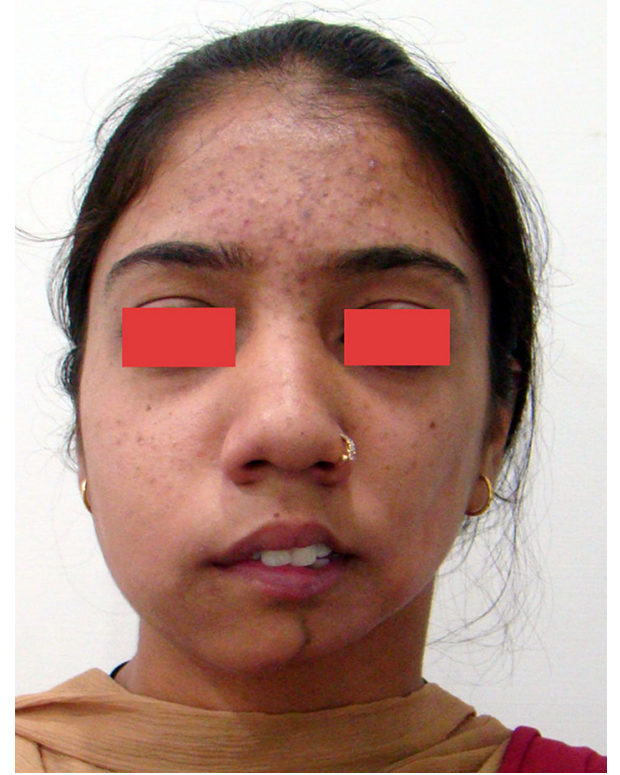

Fig. 4 Preoperative photograph of case 2 showing extensive involvement of lower and middle third of left side of face

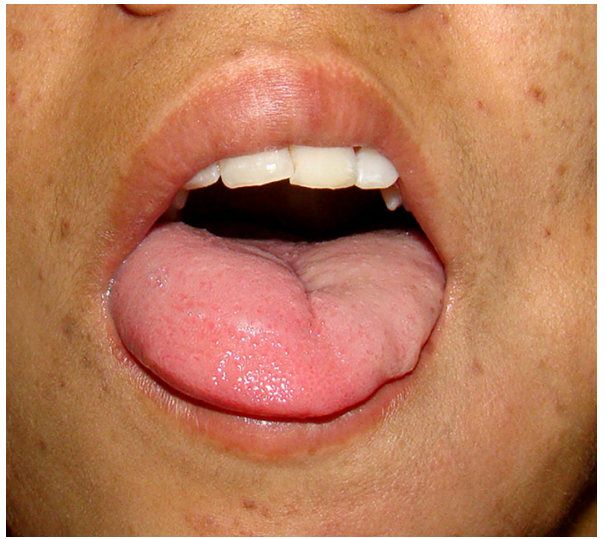

Fig. 5 Intraoral photograph showing hemiatrophy of tongue

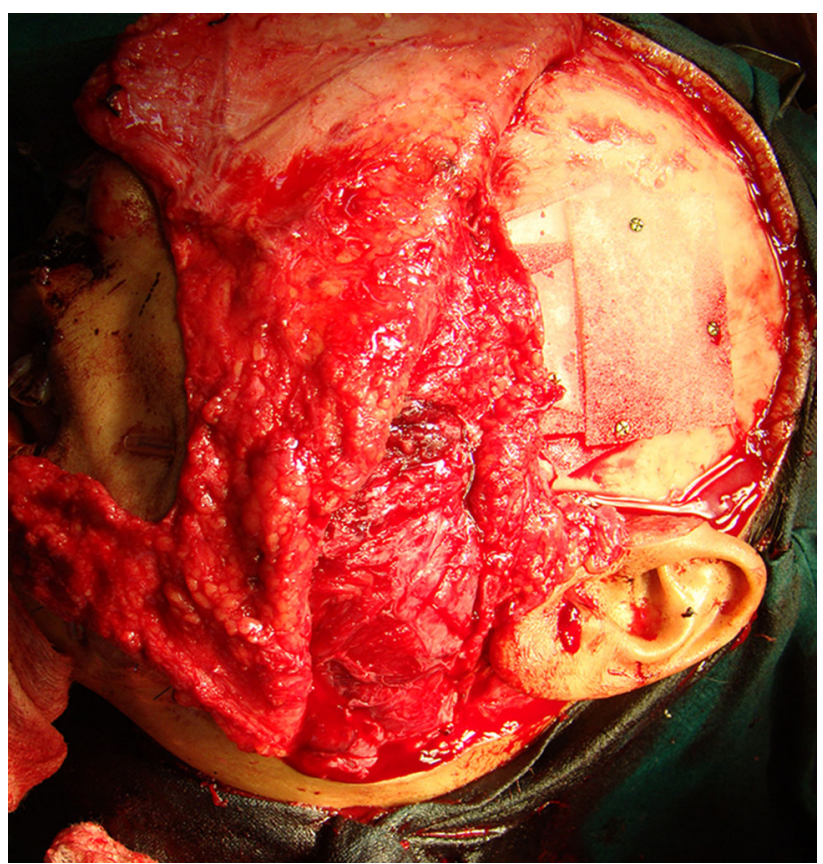

Fig. 6 Restoration of contour of angle of mandible with temporalis myofascial flap and placement of porous polyethylene implants in the temporal hollow 


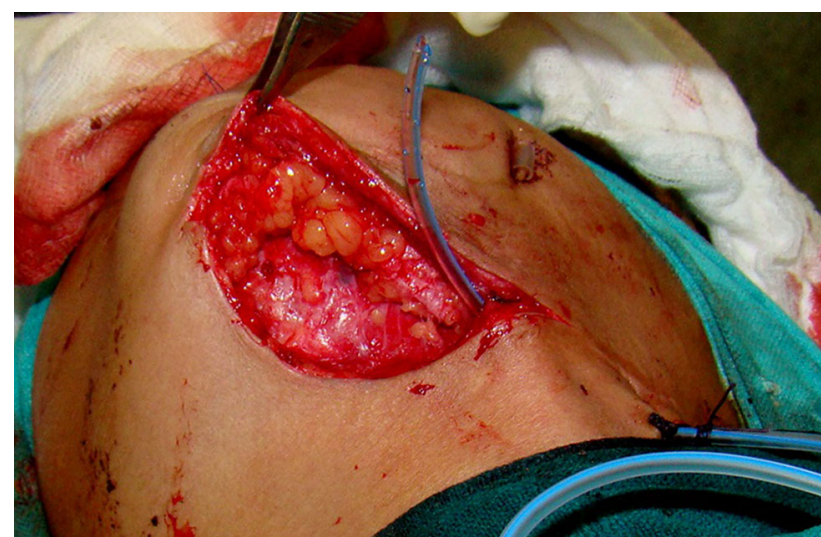

Fig. 7 Augmentation of lower lip and cheek with dermal fat

Ipsilateral progressive body atrophy is also seen in few cases [10].

The clinical features have been best described in the study by Stone of 205 cases of PRS enrolled in the Romberg Connection. Of the 205 cases, 165 were females and 40 males; median age of the patient was 32 (range 4-64); median age of onset was 10 years (range 1-50); 46 cases showed left side involvement while $52 \%$ right side involvement and $2 \%$ bilateral. Some authors advocate more common occurrence in females, a ratio of 3:2 men, while others consider the same rate between genders [13]. Forehead was involved in $63 \%$ of these cases, cheek $75 \%, 43 \%$ chin, $55 \%$ lips, $50 \%$ teeth and gums and $25 \%$ tongue. Other symptoms include epilepsy in $11 \%$, migraine $52 \%$, facial pain $46 \%$, ocular problems $46 \%$ and jaw pain or difficulty in opening or closing jaw 35\%. In few patients, other autoimmune disorders like vitiligo, thyroid problems, systemic sclerosis, inflammatory bowel disease, rheumatoid arthritis, ankylosing spondylitis, systemic lupus

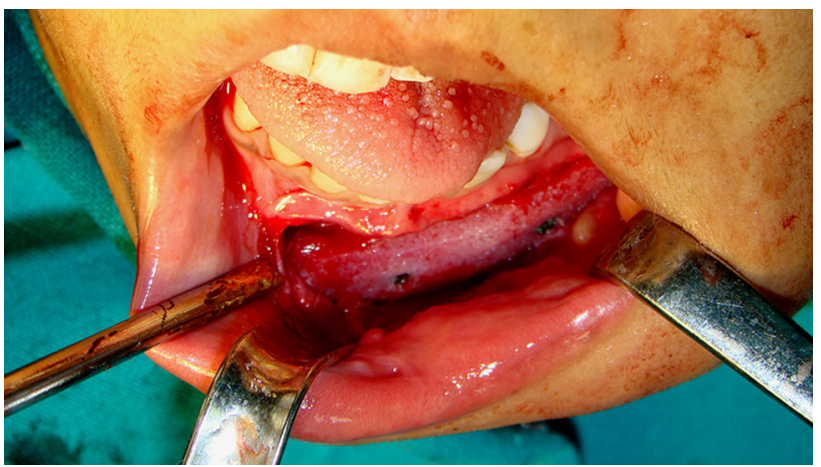

Fig. 9 Augmentation of mandible with porous polyethylene implants

erythematosus and multiple sclerosis were also found. The eye and the cheek of the affected side may appear sunken. Hair may turn white and fall off. Hyperpigmentation of the overlying skin may be seen with areas of vitiligo. Oral manifestations include atrophy of half of lips and tongue, shortening of the body of the mandible and/or ramus of the mandible, retarded tooth eruption and malformed roots. Mouth and nose are deviated to the affected side, deviating the facial and the dental midline. Atrophy of superior lip leads to excessive exposure of the teeth. The affected teeth are vital. When the disease manifests before 5 years of age, frontomaxillary defects are seen as seen in our case three [9]. Between 5 and 15 years, mandibular defects are seen and above 15 years usually soft tissue defects develop seen in our case one and two. Among our cases, the first case had only mild asymmetry of the face involving the lower half of the face with no skeletal or neurologic changes. The second case had more severe asymmetry of the cheek, upper lip and the lower face without any skeletal and neurologic signs and symptoms. She had also hemiatrophy of the tongue but no involvement of the teeth. The third
Fig. 8 a Porous polyethylene implant to augment malar area, b collagen filler for upper lip and cheek
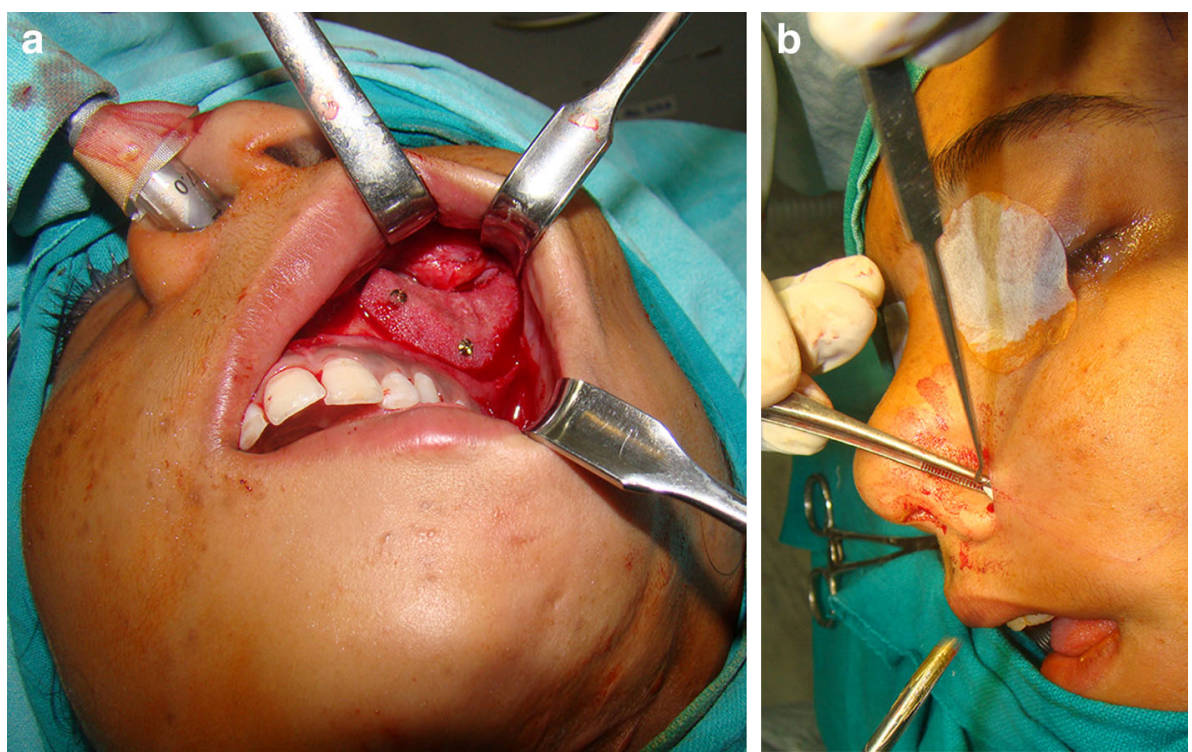


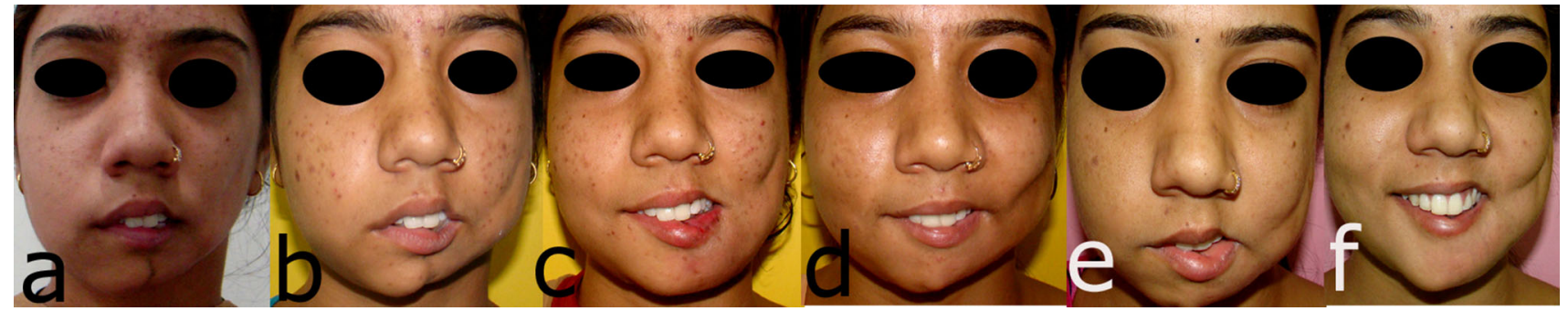

Fig. 10 Postoperative photograph of case 2 showing the progressive changes. a Preoperative, $\mathbf{b}$ after angle augmentation with temporalis flap, $\mathbf{c}$ after lower lip augmentation with dermal fat, $\mathbf{d}$ after upper lip

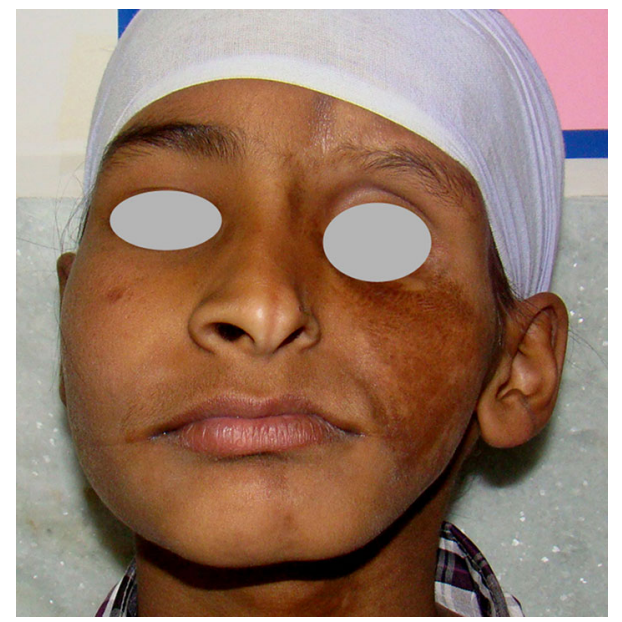

Fig. 11 Preoperative photograph of case 3 showing the severe involvement of hard and soft tissues of left side of face

case was more severe with defect in the upper and middle face, deviation of skeletal and dental midline to the affected side, enophthalmos, excessive show of teeth. However, there were no signs or symptoms of neurologic involvement.

Even though there is no cure for this disease, many attempts have been made to stop progression as well as to correct residual deformities. The response to treatment is very difficult to predict, and no clinical trials have been reported. Parry Romberg Syndrome as such is a self-limiting disease, and the need for medical treatment arises from the coexistence of other autoimmune disorders like scleroderma. Immunosuppressants like methotrexate, augmentation with collagen and porous polyethylene implant, $\mathbf{e}$ before fat injection upper lip, $\mathbf{f}$ after porous polyethylene implant on mandible

corticosteroids, cyclophosphamide and azathioprine have been used in severe and progressive cases of PRS [8]. Methotrexate is the standard therapy for active disease [3]. The dose of methotrexate ranges from 0.3 to $1 \mathrm{mg} / \mathrm{kg} / \mathrm{week}$ with a maximum weekly dose of $25 \mathrm{mg}$ in either or injectable form. It is often combined with oral prednisolone $1 \mathrm{mg} / \mathrm{kg}$ per day tapered at the end of 3 months. Another regime that has been followed is IV methylprednisolone $1000 \mathrm{mg}$ for 3 days monthly for 6 months. Current evidence supports a 12-24-month course of methotrexate to induce prolonged remission $[14,15]$. Topical treatment with calcipotriol-betamethasone dipropionate ointment applied twice daily over the hyper pigmented area was tried by Lazaridou with some success [16]. Reconstruction of the residual defects is generally carried out once the disease process stabilizes.

Actual treatment of Parry Romberg syndrome in itself is surgery for correction of residual deformities. It involves repeated procedures to achieve a long lasting result [17]. Guerrerosantos et al. [18] divided patients with PRS into four groups according to the severity of the defect to plan treatment. Type 1 patients had a mild form of the disease which can be noticed easily only by patients family or close acquaintances. There is no bony involvement. In Type 2, the defect is more obvious but do not involve hard tissue. Type 3 patients show both soft tissue and hard tissue involvement with severe deformity. Type 4 patients have more severe deformity with the skin almost attached to the bone and patients have functional problem of their lip and nose. For Types 1 and 2 patients, they recommended fat

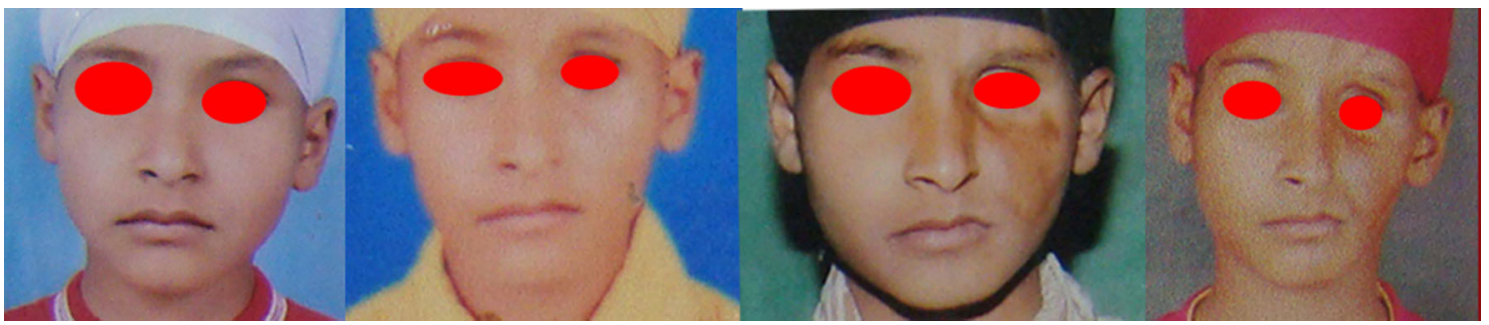

Fig. 12 Photograph showing the sudden loss of tissues of left side of face in 1 year 
Table 1 Clinical features of Parry Romberg Syndrome [5]

\begin{tabular}{ll}
\hline Clinical features & Incidence \\
\hline Facial asymmetry & $100 \%$ \\
Atrophy of the subcutaneous tissue & $100 \%$ (forehead 63\%, cheek 75\%, chin 53\%, lips 55\%) \\
Atrophy of bone and cartilage & NA \\
Maxillary and mandibular hypoplasia with deviation of the face toward affected side & NA \\
Hyperpigmentation of the skin & $20 \%$ \\
Alopecia & NA \\
Lip atrophy and unilateral exposure of teeth & NA \\
Ocular abnormalities-enophthalmos, uveitis, miosis & $46 \%$ \\
Atrophy of tongue & $25 \%$ \\
Dental abnormalities-retarded eruption, malformed roots, deviation of midline & $50 \%$ \\
Trismus, jaw symptoms like hemi-masticatory spasm & $35 \%$ \\
Migraine & $52 \%$ \\
Facial pain & $46 \%$ \\
Epilepsy & $11 \%$ \\
Brain changes on MRI & $5 \%$ \\
Hemiatrophy of ipsilateral or contralateral arm, trunk or leg & $20 \%$ \\
\hline
\end{tabular}

and cartilage graft as the treatment of choice because of the good vascularization of the recipient site. In Types 3 and 4, they suggested a galeal flap to provide greater volume and tissue softness. In Type 1 and Type 2 cases, reasonable success have been achieved by dermal fillers like silicone, collagen and medpore as well as fat injection or grafts. The advantages of fat graft include cost-effectiveness, better skin texture and more natural contours and facial expression [19]. The major drawback is the unpredictability of results and loss of volume [20]. The American Society of Plastic and Reconstructive Surgery concluded in the consensus statement in 1987 that $30 \%$ of the transferred adipose tissue remained viable after 1 year. They recommended overcorrection to compensate for this loss. Recently, stem cells and stromal vascular fraction have been used along with fat grafts to increase their predictability and better volume retention [21, 22]. There are reports of extremely rare complications like unilateral loss of vision and cerebral infarction due to fat embolism after fat grafting [19]. Types 3 and 4 required multiple major reconstructive procedures like free vascular flaps to achieve best results [23].

Mordick et al. [24] and Roddi et al. [25] conducted studies comparing the two main techniques: the fat grafting and vascularized tissue transfer. These studies showed that fat grafts are simple, affordable, with low risk of complications and good cosmetic results, especially for mild to moderate defects. However, for most severe atrophy, the transfer of vascularized tissue is more effective, due to the low vascular supply. Pieces of omentum, muscle and fasciocutaneous flaps have been used [24-30]. Many a times, the results achieved by these treatment modalities are lost with time due to resorption as well as gravity and patient may need repeated surgeries to correct the residual deformities. In our case series, the collagen filler used for correction of upper lip and cheek was lost over a period of 3 months and the dermal fat graft to the lower lip and cheek was partially lost by 1 year. However, after the last surgery of augmentation of the mandible with porous polyethylene implant, the results are stable. Recently, $3 \mathrm{D}$ reconstruction has come up in a big way in designing and fabrication of flaps and grafts for correction of such cases.

\section{Conclusion}

Parry Romberg Syndrome is a rare disorder of unknown origin which is self-limiting but can lead to severe disfigurement as well as functional deficit. Mild to moderate cases with only esthetic problems can be successfully managed by fat transplant which may require to be repeated. Severe cases will require multiple procedures to correct the soft and hard tissue deformities. Along with this, management of other symptoms like migraine, epilepsy, etc. may also be required. Diagnosis of the disease is only by the clinical features. The results of fat graft and collagen filler are unpredictable. Porous polyethylene implant gives stable results.

The institutional review board has given permission to publish this study. We have read the Helsinki Declaration and have followed the guidelines in this investigation. 
Acknowledgements Funding was provided by Government.

\section{References}

1. Jun JH, Kim HY, Jung HJ et al (2011) Parry-Romberg Syndrome with En Coup de Sabre. Ann Dermatol 23(3):342-347

2. Kumar AA, Kumar RA, Shantha GPS, Aloogopinathan G (2009) Progressive hemi facial atrophy-Parry Romberg Syndrome presenting as severe facial pain in a young man: a case report. Cases J 2:6776

3. Tolkachjov SN, Patel NG, Tollefson MM (2015) Progressive hemi facial atrophy: a review. Orphanet J Rare Dis 10:39

4. Lewkonia RM, Lowry RB (1983) Progressive hemi facial atrophy (Parry-Romberg Syndrome) report with review of genetics and nosology. Am J Med Genet 14:385-390

5. Stone J (2003) Parry Romberg Syndrome. Neurology 61(5):674-676

6. Sudarshan R (2012) Progressive hemi facial atrophy—a review. SEAJCRR 1(1):16-21

7. Sommer A, Gambichler T, Bacharach-Buhles M, von Rothenburg T, Altmeyer P, Kreuter A (2006) Clinical and serological characteristics of progressive facial hemi atrophy: a case series of 12 patients. J Am Acad Dermatol 54(2):227-233

8. Stone J (2006) Parry-Romberg Syndrome. Pract Neurol 6:185-188

9. Madasamy R, Jayanandan M, Adhavan UR, Gopalakrishnan S, Mahendra L (2012) Parry Romberg Syndrome: a case report \& discussion. J Oral Maxillofac Pathol 16(3):406-410

10. Deshingkar SA, Barpande SR, Bhavthankar JD, Humbe JG (2012) Progressive hemi facial atrophy (Parry-Romberg Syndrome). Contemp Clin Dent 3:S78-S81

11. Maletic J, Tsirka V, Loannides P, Karacostas D, Taskos N (2010) Parry-Romberg Syndrome associated with localized scleroderma. Case Rep Neurol 2:57-62

12. Tollefson MM, Witman PM (2007) En Coup de Sabre morphea and Parry-Romberg Syndrome: a retrospective review of 54 patients. J Am Acad Dermatol 56:257-263

13. Nasser IJG, Balbinot P, Kurogi AS et al (2013) Romberg's syndrome: a series of cases. Rev Bras Cir Plast 28(2):201-204

14. Goldberg-Stern H, de Grauw T, Passo M, BallJr WS (1997) Parry Romberg Syndrome: follow up imaging during suppressive therapy. Neuroradiology 39(12):873-876

15. Korkmaz C, Adapinar B, Uysal S (2005) Beneficial effect of immunosuppressive drugs on Parry Romberg Syndrome: a case report and review of literature. South Med J 98(9):940-942

16. Lazaridou E, Giannopoulou C, Apalla Z, Fotiadou C, Trigoni A, Loannides D (2010) Parry-Romberg Syndrome. J Dermatol Case Rep 2:30-32
17. Slack GC, Tabit CJ, Allam KA, Kawamoto HK, Bradley JP (2012) Parry Romberg reconstruction: optimal timing for hard and soft tissue procedures. J Craniofac Surg 23(7 Suppl 1):1969-1973

18. Guerrerosantos J, Guerrerosantos F, Orozco J (2007) Classification and treatment of facial atrophy in Parry Romberg disease. Aesthetic Plast Surg 31(5):424-434

19. Alencar JCG, Andrade SHC, Pessoa SGP, Dias IS (2011) Autologous fat transplantation for the treatment of progressive hemi facial atrophy (Parry-Romberg Syndrome: a case report and review of medical literature). An Bras Dermatol 86(4 Suppl 1):585-588

20. Hunstad JP, Shifrin DA, Kortesis BG (2011) Successful treatment of Parry Romberg Syndrome with autologous fat grafting: 14 year follow-up and review. Ann Plast Surg 67(4):423-425

21. Koh KS, Oh TS, Kim H et al (2012) Clinical application of human adipose tissue derived stem cells in progressive hemi facial atrophy (Parry Romberg Syndrome) with micro fat grafting techniques using 3-dimensional computed tomography and 3-dimensional camera. Ann Plast Surg 69(3):331-337

22. Garza RM, Rennert RC, Paik KJ, Atashroo D et al (2015) Studies in fat grafting: Part IV. Adipose-derived stromal gene expression in cell assisted lipotransfer. Plast Reconstr Surg 135(4):1045-1055

23. Hu J, Yin L, Tang X, Gui L, Zhang Z (2011) Combined skeletal and soft tissue reconstruction for severe Parry Romberg Syndrome. J Craniofac Surg 22(3):937-941

24. Mordick TG 2nd, Larossa D, Whitaker L (1992) Soft-tissue reconstruction of the face: a comparison of dermal-fat grafting and vascularized tissue transfer. Ann Plast Surg 29(5):390-396

25. Roddi R, Riggio E, Gilbert PM, Hovius SE, Vaandrager JM, van der Meulen JC (1994) Clinical evaluation of techniques used in the surgical treatment of progressive hemi facial atrophy. J Craniomaxillofac Surg 22(1):23-32

26. Pisarek W (1988) Reconstruction of craniofacial macrosomia and hemi facial atrophy with free latissimus dorsi flap. Acta Chir Plast 30:194-201

27. Namba Y, Ito S, Tsutsui T, Kohima I (2005) Facial augmentation with groin osteoadiposal flap transfer. J Reconst Microsurg 52:118-127

28. Asai S, Kamei Y, Nishibori K, Katoh T, Torii S (2006) Reconstruction of Romberg disease defects by omental flap. Ann Plast Surg 57:154-158

29. Gulati S, Jain V, Garg G (2006) Parry Romberg Syndrome. Indian J Pediatr 73(5):448-449

30. Cheng J, Shen G, Tang Y, Zhang Z, Qiu W, Lu X (2010) Facial reconstruction with vascularized serratus anterior muscle flap in patients with Parry-Romberg Syndrome. Br J Oral Maxillofac Surg 48:261-266 